\title{
Approximate Confidence Limits for the Concentration of Insulin in Radioimmunoassay*
}

\author{
M. Brown, M. Doron and Z. Laron \\ Department of Statistics, and Institute of Paediatric and Adolescent Endocrinology Beilinson Hospital, Petah Tikva, \\ Tel Aviv University, Israel \\ Received: April 11, 1973, and in revised form: September 7, 1973
}

\begin{abstract}
Summary. In radioimmunoassays confidence limits for the concentration of insulin in the serum assayed are of value to the laboratory as an aid in quality control and to the doctor as an aid in differentiating high from low concentrations and in the reliability to be placed on the result. We present a method of deriving approximate confidence intervals for the concentrations by approximat-
\end{abstract}

ing the non-linear standard curve by a straight line (its tangent) at the estimated concentration. A similar ap. proach may be used for other non-linear standard curves.

Key words: Insulin radioimmunoassay, statistical evaluation, reliability of insulin assay, confidence limits of insulin assay, use of computer in radioimmumoassays.
The estimation of hormone concentrations in biological fluids by radioimmunological methods, developed in recent years, has greatly advanced our knowledge of the role of various hormones in health and disease. However, several new problems have become apparent: a) the concentration of the estimated immunoreactive hormone does not always express its biological activity; in fact the possibility of a dissociation between these two activities under certain conditions has been proposed [4], and b) technical difficulties arising with the rather complicated radioassays. Consequent upon the latter are problems in the presentation and interpretation of the results obtained by these assays.

Radioimmunoassays typically result in non-linear dose-response curves. In an intensive study comparing sereral possible formulae to represent the insulin standard curve, Täljedal and Wold [7] selected the following formula as the best fitting: $Y=1 /(a X+b)+$ c. In the above $Y$ is the radioactive count at the concentration $X$ of unlabelled insulin and $a, b$ and $c$ are parameters which are empirically determined. Using 10 standard curves for human insulin used in routine assays, each having two replicates at each of seven points $(0,5,10,20,50,100,200 \mu \mathrm{U} / \mathrm{ml})$, we performed a similar comparison of functional forms and arrived at a like conclusion.

A more limited approach has been taken by Morgan et al. [5], who fitted $Y=a \log X+b$ to the linear portion of the standard curve and indicate concentrations outside that segment to be extreme, without an estimate of the value. Burger et al. [2] used a model of the form $Y-a /\left(b+X^{c}\right)$ which, by the proper choice of parameters, can approximate that of Täljedal-Wold.

Rodbard and Cooper [6] discussed the various sources of error in the performance and analysis of

* This work has been supported in part by USPHS NIH Grant No. RR-3 at the Health Sciences Computing Facility, University of California, Los Angeles. radioimmunoassays, with emphasis on those for human growth hormone and human luteinizing hormone. They derived confidence limits for the potency estimates in the more usual logit-log model by assuming that the estimates of the parameters have no errors. Such confidence limits are of value in assessing the quality control of the laboratory and the clinical reliability of the estimate.

Using the Täljedal-Wold model we have derived approximate confidence intervals for the assayed concentrations of insulin. The use of these confidence lim. its for quality control is illustrated. It should be noted that this method, in common with other previously presented methods, does not consider the problem of between assay variation, but assumes that no major technical problem affected the performance of the assay.

\section{Method}

Insulin was determined by radioimmunoassay, by the method of Hales and Randle [3], using the Insulin Radioimmunoassay Kit produced by the Radiochemical Centre, Amersham, England. Human insulin standard was Batch K 3096 and insulin binding reagent Batch K 3820. Oxoid filters were used for the separation of free and bound $\mathrm{I}^{125}$ insulin.

\section{Estimating the Model}

The statistical model assumed is $Y=1 /(a X+b)+$ $c+\Sigma$ where the error $\Sigma$ is normally distributed with mean zero and constant variance $\left(\sigma^{2}\right)$. In our standards no elear relationship has been noted between the concentration of unlabelled insulin and the variance at that concentration. A similar error distribution is assumed by Burger et al. [2].

It is usually assumed that the error variance is not constant over the whole range of the standard curve 
[7]. When the error variance can be expressed as a function of the concentration of unlabelled insulin, weighted regression should be used in place of the unweighted regression proposed here. Since there are many sources of variation in the performance of a radioimmunoassay [6], caution is recommended in estimating this relationship on the basis of only a few standard curves. Using ten standard curves we were unable to identify any such relationship.

The values of $a, b$ and $c$ are found by iteration on $\mathrm{c}$. First $c$ is chosen and then $a$ and $b$ found by ordinary least squares. This is repeated with different $c$ 's until the sum of squares of deviations of the observed counts from the model is minimized.

\section{Approximate Confidence Limits for the Insulin Concen- trations}

Let $y_{0}$ be the counts for the serum being tested, then the concentration $\left(x_{0}\right)$ of insulin is estimated by $X=\left(1 /\left(y_{0}-c\right)-b\right) / a$.

If the equation for the standard curve was of linear form $(Y=a+b X)$, then Brownlee [1] (page 346) gives the confidence limits of $x$ given on observed $y$. However, the Täljedal-Wold model [7] cannot be written in linear form.

Therefore, we approximated the standard curve at $y_{0}$, the radioactive counts of the serum, by a straight line which is tangent to the curve. On this line we find the bounds for $x_{0}$, the estimate of insulin. This will give approximate limits which are slightly low at both the upper and lower end. This small bias should not affect the interpretation of the results and may be corrected for by a modification of the method. The next paragraph details the formulae for the calculation.

The equation of the tangent to the curve

at $\left(x_{0}, y_{0}\right)$ is

$$
Y=\frac{1}{a X+b}+c
$$

where

$$
y=\alpha+\beta(x-\bar{X})
$$

$$
\begin{gathered}
\beta=-a /\left(a x_{0}+b\right)^{2} \\
\alpha=y_{0}-\beta\left(x_{0}-\bar{X}\right) \\
\bar{X}=\text { mean of the } X \text { 's in the standard }
\end{gathered}
$$

Then $\alpha$ and $\beta$ are substituted in the following to give a confidence limit for $x_{0}$

$$
\bar{X}+\frac{\beta\left(y_{o}-\alpha\right)}{D}+\frac{t s}{D}\left[D\left(\frac{1}{m}+\frac{1}{k}\right)+\frac{y_{o}-\alpha}{\Sigma\left(X_{i}-\bar{X}\right)^{2}}\right]^{1 / 2}
$$

where

$D=\beta^{2}-\frac{t^{2} s^{2}}{\sum\left(X_{i}-\bar{X}\right)^{2}}$

$\Sigma(X-\bar{X})^{2}=$ sum of squares of deviations from the mean for all the $X^{\prime}$ 's in the standard

$s=$ standard deviation of observations (residuals) from the standard curve $m=$ number of observations in the standard

$k=$ number of readings taken on the blood serum for which $y_{0}$ is the average

and $t$ is chosen from the student's $t$-table with $m-3$ degrees of freedom according to which percentile limit is desired.

\section{Results and Conclusions}

The data for a typical standard is given in Table 1. The expected values of the counts at each dose is cal-

\begin{tabular}{|c|c|c|c|}
\hline $\begin{array}{l}\text { Insulin } \\
\text { standard } \\
(\mu \mathrm{U} / \mathrm{ml}) \\
(\mathrm{X})\end{array}$ & $\begin{array}{l}\text { Radio- } \\
\text { active } \\
\text { counts } \\
(\mathrm{Y})\end{array}$ & $\begin{array}{l}\text { Expected } \\
\text { counts } \\
\text { (by Formula) }\end{array}$ & $\begin{array}{l}\text { Error: } \\
\text { Observed counts - } \\
\text { expected counts }\end{array}$ \\
\hline 0 & 9274 & 9269 & 5 \\
\hline 0 & 9522 & 9269 & 253 \\
\hline 5 & 8082 & 8278 & -196 \\
\hline 5 & 8354 & 8278 & 76 \\
\hline 10 & 7296 & 7481 & -185 \\
\hline 10 & 7518 & 7481 & 37 \\
\hline 25 & 5864 & 5811 & 53 \\
\hline 25 & 5974 & 5811 & 163 \\
\hline 50 & 4396 & 4247 & 149 \\
\hline 50 & 4110 & 4247 & -137 \\
\hline 100 & 2830 & 2780 & 50 \\
\hline 100 & 2674 & 2780 & -106 \\
\hline 200 & 1798 & 1669 & 129 \\
\hline 200 & 1566 & 1669 & -103 \\
\hline
\end{tabular}
culated from the model and the residuals are listed. The standard deviation from the regression is given as 152.4. Since the minimum standard deviation possible

Table 1. The radioactive counts $(Y)$ corresponding to various levels of the insulin standard (X) using duplicate samples

is $\sqrt{9522 \sim 97}$ based upon only Poisson error, whereas the sources of other errors are numerous [6], we are satisfied with the observed standard deviation. In addition, the pattern of the residuals appears quite random: no two large residuals appear at the same dosage; no very large residual is present; nor is there a pattern of many residuals of the same sign in a row. Therefore, we accept the fitted model.

Data for 4 patients are given in Table 2. Each serum is assayed in triplicate and the concentration calculated for each of the three samples and the mean of the three. Ninety percent confidence limits are also produced. When the confidence limits of one sample do not overlap the other two, then there is reasonable likelihood that an incorrect result has been recorded. Otherwise the confidence limits reported is that of the mean which has the shortest interval since it is based on the most observations.

As is well-known, the confidence interval at low concentrations of insulin is much smaller than at high 
concentrations. A similar effect results when using the logit-log model.

It is clear that we would want to perform our assays in that region of the standard curve for which the relative error of the estimate of insulin is as small as possible. As this method yields a confidence interval for each estimate, the region of the curve in which assays optimally should be performed is that region where the ratio of the confidence interval to the estimate is as small as possible.

Table 2. 90\% confidence limits for insulin in blood serum based on the standard in Table 1. Triplicate readings and the mean of the three readings

\begin{tabular}{llcl}
\hline $\begin{array}{l}\text { Pationt } \\
\text { No. }\end{array}$ & $\begin{array}{l}\text { Radioactive } \\
\text { count }\end{array}$ & $\begin{array}{l}\text { Estimated } \\
\text { insulin } \\
(\mu \mathrm{U} / \mathrm{ml})\end{array}$ & $\begin{array}{l}90 \% \text { Confidence } \\
\text { limits }\end{array}$ \\
\hline 1 & 4166 & 51.8 & $(45.3,58.3)$ \\
& 4371 & 47.4 & $(\mathbf{4 1 . 5 , 5 3 . 2 )}$ \\
Mean & 4221 & 50.6 & $(44.3,56.9)$ \\
2 & 4253 & 49.9 & $(46.0,53.7)$ \\
& 2214 & 137.8 & $(113.2,163.8)$ \\
Mean & 2168 & 141.8 & $(116.0,169.2)$ \\
3 & 2158 & 142.7 & $(116.7,170.4)$ \\
& 6695 & 140.7 & $(124.2,158.9)$ \\
Mean & 6560 & 16.1 & $(13.6,18.6)$ \\
4 & 6492 & 17.3 & $(14.7,19.9)$ \\
& 3168 & 17.9 & $(15.3,20.6)$ \\
Mean & 3531 & 17.1 & $(15.5,18.7)$ \\
\hline
\end{tabular}

In our clinical practice we find the presentation of insulin determinations as the mean values and $90 \%$ confidence limits of great help in the interpretation of the results. The meaning of each determination assumes different proportions when confidence limits are known.

Details of the computer program are available from the authors.

\section{References}

1. Brownlee, K.A.: Statistical theory and methodology in science and engineering. 2nd ed. New York: John Wiley \& Sons 1965

2. Burger, H.G., Lee, V.W.K., Rennie, G.C.: A generalized computer program for the treatment of data from competitive proteinbinding assays including radioimmunoassays, J. Lab. clin. Med. 80, 302-312 (1972)

3. Hales, C.N., Randle, P.J.: Biochem. J. 88, 137-146 (1963)

4. Laron, Z., Pertzelan, A., Karp, M.: Pituitary dwarfism with high serum levels of growth hormone. Israel $J$. Med. Sci. 4, 883-894 (1968)

5. Morgan, C.R., Hardigg, J.B., Fisher, D.D.: A computer program for immunoassay of protein hormone with special reference to insulin and growth hormone. Diabetes 16, 734-737 (1967)

6. Rodbard, D., Cooper, J.A.: A model for prediction of confidence limits in radioimmunoassays and competitive protein binding assays. In: In vitro procedures with radioisotopes in medicine, pp. 659-673. Vienna: International Atomic Energy Agency 1970

7. Täljedal, I.B., Wold, S.: Fit of some analytic functions to radioimmunoassay standard curves. Biochem. J. $119,139-143(1970)$

Prof. Z. Laron

Institute of Pediatric and Adolescent

Endocrinology

Beilinson Hospital

Petah Tikva

Israel 